\title{
Analisis Pengendalian Kualitas Produk Air Minum Dalam Kemasan dengan Menggunakan Statistical Process Control (SPC) dan Kaizen Pada PT. Tujuh Impian Bersama Kabupaten Jember
}

\author{
(The Analysis of Quality Control In Bottled Water Using Statistical Process Control (SPC) \\ and Kaizen In PT. Tujuh Impian Bersama Districts Jember)
}

\author{
Marga Area Refangga, Didik Pudjo Musmedi ${ }^{1}$, Eka Bambang Gusminto \\ Manajemen, Fakultas Ekonomi dan Bisnis, Universitas Jember (UNEJ) \\ Jln. Kalimantan 37, Jember 68121 \\ E-mail: margaarea@gmail.com
}

\begin{abstract}
Abstrak
Penelitian ini bertujuan untuk menganalisis tingkat kerusakan dan mengidentifikasi faktor-faktor penyebab kerusakan AMDK 220ml yang terjadi pada tanggal 13 Maret sampai dengan 11 April 2017 pada PT. Tujuh Impian Bersama. Perusahaan ini bergerak dalam industri air minum dalam kemasan (AMDK) dengan merek Al Qodiri. Penelitian ini menggunakan model penelitian deskriptif statistik. Analisis yang digunakan yaitu dengan Statistical Process Control (SPC) dan Kaizen. Hasil analisis menunjukkan bahwa pengendendalian kualitas produk berada di luar batas kendali yang ditetapkan. Jenis kerusakan paling banyak adalah kemasan penyok sebanyak 239pcs. Dari diagram sebab akibat dapat diketahui faktor penyebab kerusakan dari yang paling dominan meliputi mesin, bahan baku, manusia, dan metode. Berdasarkan alat-alat implementasi kaizen maka rekomendasi perbaikan yang diperoleh adalah perawatan rutin dan penyetelan ulang terhadap mesin produksi, pemilihan lebih teliti terhadap supplier dengan standar yang lebih ketat, dan peningkatan kinerja sumber daya manusia melalui pengawasan dan briefing.
\end{abstract}

Kata Kunci: AMDK, Kaizen, Pengendalian Kualitas, Statistical Process Control (SPC)

\begin{abstract}
This research aims to analyze the level of damage and identify factors causing damage AMDK $220 \mathrm{ml}$ that occurred on March 13 to 11 April 2017 at PT. Tujuh Impian Bersama. The company is engaged in bottled drinking water industry (AMDK) with Al Qodiri brand. This research uses descriptive statistical research model. The analysis used is Statistical Process Control (SPC) and Kaizen. The results of the analysis show that the quality control of the product is beyond the control limits set. The most damage type is dent pack as much as 239pcs. From the causal diagram can be known factors causing damage from the most dominant include machinery, raw materials, humans, and methods. Based on the kaizen implementation tools, the recommendations for improvement are routine maintenance and re-adjustment of production machines, more rigorous selection of suppliers with more stringent standards, and improved human resource performance through supervision and briefing.
\end{abstract}

Keywords: Bottled Water, Kaizen, Quality Control, Statistical Process Control

\section{Pendahuluan}

Air merupakan kebutuhan penting bagi keberlangsungan hidup manusia. Senyawa ini berperan penting dalam tubuh manusia terutama untuk menjaga kadar cairan tubuh. Berdasarkan Keputusan Menteri Perindustrian dan Perdagangan Republik Indonesia No. 167/1997, AMDK memiliki definisi yang jelas, yaitu air yang telah diolah dan dikemas serta aman untuk diminum. AMDK dipilih karena selain praktis dan higienis, juga bisa diminum sewaktuwaktu dan di mana saja. Selain itu, dengan pertumbuhan penduduk yang semakin pesat hal ini akan berbanding lurus dengan permintaan akan AMDK. Air minum yang merupakan kebutuhan pokok kemudian dengan jumlah konsumen yang besar, maka dengan sendirinya akan menciptakan peluang pasar untuk kebutuhan akan AMDK yang senantiasa meningkat. Peluang ini harus dimanfaatkan bagi pelaku usaha terkait untuk memperoleh keuntungan.

Namun, peluang tersebut bukan berdiri tanpa risiko.
Perusahaan harus berusaha lebih ekstra untuk bisa bersaing dalam menghadapi kebutuhan pasar. Kinerja perusahaan melalui manajemen yang tepat akan menghasilkan keuntungan bagi perusahaan melalui produk yang dihasilkan dengan baik dan konsumen yang berhasil dipertahankan melalui pelayanan yang optimal. Kedua hal tersebut bisa diraih perusahaan dengan menaruh perhatian terhadap aspek kualitas.

Kualitas kemudian menjadi pertimbangan penting dan tidak bisa dipandang sebelah mata. Keadaan demikian semakin menuntut performa prima bagi setiap perusahaan atau industri yang terkait. Suatu produk dikatakan berkualitas baik apabila dapat memenuhi kebutuhan dan keinginan pelanggan atau dapat diterima oleh pelanggan sebagai batas spesifikasi, dan proses yang baik yang diberikan oleh produsen sebagai batas kontrol. Dengan demikian kualitas dapat diartikan sebagai tingkat atau ukuran kesesuaian suatu produk dengan pemakainya, dalam arti sempit kualitas diartikan sebagai tingkat kesesuaian produk dengan standar yang telah

1Corresponding Author 
ditetapkan. (Alisjahbana, 2005). Dalam rangka menjaga kualitas produk, para pelaku usaha dituntut mengidentifikasi upaya-upaya perbaikan yang perlu dilakukan dan memenuhi standar yang di tetapkan oleh badan lokal dan internasional yang mengelola tentang standarisasi mutu/kualitas inilah yang disebut pengendalian kualitas.

Kabupaten Jember sendiri memiliki beberapa produsen air minum dalam kemasan. Salah satu produsen air minum tersebut adalah PT. Tujuh Impian Bersama. Perusahaan ini memproduksi air minum dalam kemasan dengan merk $\mathrm{Al}$ Qodiri Barokah Mineral Water. Produk dari perusahaan ini terbukti memiliki pangsa pasar besar meliputi wilayah pemasaran Karesidenan Besuki (Jember, Banyuwangi, Situbondo, dan Bondowoso) serta di luar Karisdenan Besuki meliputi Probolinggo, Lumajang, Pasuruan, dan Bali. Al Qodiri juga telah tersedia di ritel modern seperti Indomaret Se-Karesidenan Besuki, Alfamart Se-Karesidenan Besuki dan Pasuruan serta ritel modern lainnya di Kabupaten Jember.

PT. Tujuh Impian Bersama telah berdiri sejak tahun 2012. Lokasi perusahaan berada di Jl. Cendrawasih No. 9 Jember. Produk AMDK terbagi menjadi beberapa kemasan antara lain $120 \mathrm{ml}, 220 \mathrm{ml}, 330 \mathrm{ml}, 600 \mathrm{ml}, 1500 \mathrm{ml}$ dan kemasan galon 19liter. Untuk tahap awal, perusahaan ini mampu memproduksi AMDK dalam kemasan gelas $220 \mathrm{ml}$ sebanyak 120.000 gelas dan 15.000 kemasan botol 600ml setiap shiftnya. Perusahaan ini memiliki komitmen menjadi perusahaan yang memberikan hasil yang berkualitas tinggi, menyehatkan dan menyegarkan serta memberikan pelayanan terbaik untuk konsumen. Salah satu usaha perusahaan untuk mewujudkan komitmen tersebut adalah dengan menerapkan pengendalian kualitas pada keseluruhan proses produksi AMDK mulai dari penyiapan bahan baku hingga produk jadi. Proses produksi dilakukan secara higienis melalui mesin reversis osmosis (RO), 3 tahap macrofiltrasi dan 5 tahap microfiltrasi serta sterilisasi ultraviolet dan ozonisasi.

Namun, hal ini tidak menjamin secara penuh produk yang dihasilkan bebas dari kerusakan / cacat (zero defect) dikarenakan faktor yang menyebabkan defect berasal dari berbagai hal baik dari segi tenaga kerja, metode maupun mesin. Obyek yang dijadikan dalam penelitian ini adalah AMDK ukuran gelas $220 \mathrm{ml}$. Hal ini dipilih karena ukuran ini paling banyak diminati konsumen terbukti dari jumlah produksinya yang lebih banyak dan lebih sering dari kemasan yang lain untuk memenuhi permintaan pasar. Produk yang paling banyak beredar di pasar akan menentukan brand image perusahaan dan akan mempengaruhi persepsi konsumen terhadap produk serta sebagai bahan pertimbangan konsumen sebelum melakukan keputusan pembelian. Alasan lainnya adalah kerusakan yang terjadi di kemasan $220 \mathrm{ml}$ tidak bisa diperbaiki (reject), berbeda dengan kemasan lain seperti ukuran $600 \mathrm{ml}$ dan $1500 \mathrm{ml}$ yang sebagian besar kerusakannya bisa diperbaiki.

Produk AMDK 220ml yang mengalami kerusakan terlihat dari adanya beberapa kerusakan atau ketidaksesuaian keadaan produk akhir dari spesifikasi yang telah ditentukan (defect), seperti masalah kerusakan cup, masalah kerusakan lid, benda asing, dan trimming di mana kesemuanya disebabkan oleh beberapa faktor di tiap-tiap bagian proses produksi. Maka, dengan analisa pengendalian kualitas ini diharapkan dapat mencari sebab masih terjadinya kecacatan serta mencari solusi perbaikan dengan menggunakan alat bantu statistik sehingga persentase produk rusak dapat ditekan menjadi sekecil mungkin.

SPC (Statistical Process Control) adalah teknik ilmiah yang sangat baik untuk mengendalikan kualitas produk dengan berfokus pada proses. Metode statistik ini membantu memahami asal variasi proses yang terjadi, di mana proses produksi dikendalikan kualitasnya. Sedangkan Kaizen sendiri merupakan istilah dalam bahasa Jepang terhadap konsep Continous Incremental Improvement. Kai berarti perubahan dan Zen berarti baik. Kaizen berarti penyempurnaan yang berkesinambungan yang melibatkan setiap orang. Kaizen berguna untuk melakukan penetapan rencana tindakan untuk melaksanakan peningkatan kualitas. Penggunaan kedua teknik ini memungkin kan perusahaan untuk mengantisipasi, mengidentifikasi, dan mengoreksi kesalahan.

Berdasarkan uraian diatas, peneliti tertarik untuk meneliti pengendalian kualitas produk AMDK $220 \mathrm{ml}$ pada PT. Tujuh Impian Bersama dengan judul Analisis Pengendalian Kualitas Produk Air Minum Dalam Kemasan dengan Menggunakan Statistical Proccess Control (SPC) dan Kaizen pada PT. Tujuh Impian Bersama Kabupaten Jember. Diharapkan dalam penelitian ini dapat menjadi bahan pertimbangan bagi perusahaan untuk memperbaiki dan terus meningkatkan kualitas produknya.

\section{Metode Penelitian}

\section{Rancangan Penelitian}

Rancangan penelitian dalam artikel ini adalah quantitative descriptive.

\section{Jenis dan Sumber Data}

Jenis data yang digunakan dalam artikel ini adalah data kuantitatif dan data kualitatif. Sumber data dalam penelitian ini menggunakan data primer dan sekunder. Data primer berupa data produk rusak yang terjadi selama periode 13 Maret - 11 April 2017 (30 hari) dan hasil wawancara dengan karyawan PT. Tujuh Impian Bersama. Sedangkan data sekunder yang digunakan adalah data yang diperoleh dar data produksi perusahaan, brosur company profile, dan informasi lainnya seperti kumpulan jurnal, skripsi dari peneliti lain, buku dan internet.

\section{Metode Analisis Data}

Adapun langkah-langkah yang dilakukan adalah sebagai berikut :

a. Mengumpulkan Data Jumlah Produksi dan Produk yang Rusak/Cacat Menggunakan Check Sheet

b. Menggunakan Histogram

c. Menggunakan Peta Kendali P (P-chart)

d. Mencari Faktor Penyebab Paling Dominan dengan Menggunakan Diagram Tulang Ikan (Fishbone Chart)

e. Membuat Rekomendasi/Usulan Perbaikan Kualitas dengan Metode 5S dan Metode 5W+1H

\section{Hasil dan Pembahasan}

\section{Hasil}


Mengumpulkan Data Jumlah Produksi dan Produk yang Rusak/Cacat Menggunakan Check Sheet

Tabel 1. Check Sheet AMDK 220ml 13 Maret- 11 April

\begin{tabular}{|c|c|c|c|c|c|c|c|c|c|c|}
\hline \multirow{2}{*}{ Tgl } & \multirow{2}{*}{$\begin{array}{c}\text { Jumlah } \\
\text { Produksi } \\
\text { (pcs) }\end{array}$} & \multicolumn{8}{|c|}{ Jenis Kerusakan (pcs) } & \multirow{2}{*}{$\begin{array}{c}\text { Jumlah } \\
\text { Rusak } \\
\text { (pcs) }\end{array}$} \\
\hline & & KB & KP & LM & LT & LK & LB & $\mathrm{TR}$ & BA & \\
\hline 13 & \multicolumn{10}{|c|}{ PRODUKSI DIALIHKAN BOTOL DAN GALON } \\
\hline 14 & 48.480 & - & 1 & - & - & - & - & - & - & 1 \\
\hline 15 & 89.568 & - & 7 & - & 4 & - & - & - & - & 11 \\
\hline 16 & 118.992 & - & 15 & - & 3 & - & - & - & 2 & 20 \\
\hline 17 & 86.256 & - & 8 & - & - & 2 & - & - & 2 & 12 \\
\hline 18 & 110.448 & - & 26 & 40 & 5 & - & - & - & 4 & 75 \\
\hline 19 & \multicolumn{10}{|c|}{ HARI MINGGU LIBUR PRODUKSI } \\
\hline 20 & 131.088 & 8 & 13 & - & - & 5 & - & 20 & 3 & 49 \\
\hline 21 & 107.760 & 10 & 18 & 23 & - & 2 & - & - & 2 & 55 \\
\hline 22 & 110.640 & 5 & 6 & 15 & 8 & - & 12 & 20 & 1 & 67 \\
\hline 23 & 127.680 & - & 15 & 15 & 75 & - & 12 & - & 22 & 139 \\
\hline 24 & & & & & & & & & & \\
\hline
\end{tabular}

\section{HARI MINGGU LIBUR PRODUKSI}

$115.680 \quad-\quad 20 \quad 3 \quad 5 \quad-\quad-\quad \begin{array}{lllll}8 & 8 & 36\end{array}$

$78.000-19-5-\quad-\quad-\quad-8727$

$\begin{array}{llllllllll}131.088 & 2 & 18 & - & - & - & 5 & 6 & 8 & 39\end{array}$

$99.168 \quad-\quad 10 \quad 10 \quad 6 \quad-\quad 5 \quad 7 \quad 3 \quad 41$

HARI LIBUR PRODUKSI

HARI MINGGU LIBUR PRODUKSI

$\begin{array}{cccccccccc}81.168 & - & 6 & - & 4 & - & 3 & 7 & 10 & 30 \\ 122.400 & - & 8 & - & 8 & - & 2 & 11 & 12 & 41 \\ 106.704 & - & 11 & - & - & 6 & 3 & 6 & 8 & 34\end{array}$

PRODUKSI DIALIHKAN BOTOL DAN GALON

$8 \quad 113.184-14$ - $\quad$ - $\quad$ - $\quad$ - 519

HARI MINGGU LIBUR PRODUKSI

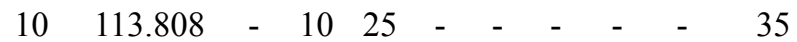

\begin{tabular}{ccccccccccc}
11 & 178.416 & - & 14 & - & 4 & - & - & - & 3 & 21 \\
\hline Total 2.070 .528 & 25 & 239 & 131 & 122 & 15 & 42 & 77 & 101 & 752
\end{tabular}

$\begin{array}{lllll}\mathrm{KB} & \text { : Kemasan Bocor } & \text { LK } & : \text { Lid Kendur }\end{array}$

KP : Kemasan Penyok LB : Lid Bocor

LM : Lid Miring

LT : Lid Terbuka

TR : Trimming

BA : Benda Asing

Sumber: Data Diolah dari PT. Tujuh Impian Bersama

Kabupaten Jember

\section{Menggunakan Histogram}

Histogram yang dibuat berdasarkan data check sheet produk rusak AMDK 220ml pada tanggal 13 Maret-11 April 2017 tabel 1. Histogram disajikan dalam gambar 1 berikut:

KB : Kemasan Bocor LK : Lid Kendur

KP : Kemasan Penyok LB : Lid Bocor

LM : Lid Miring $\quad$ TR : Trimming

LT : Lid Terbuka BA : Benda Asing

Gambar 1. Histogram Kerusakan Produk AMDK 220ml

Sumber: Tabel 1

\section{Menggunakan Peta Kendali P (P-chart)}

Langkah-langkah membuat peta kendali P (p-chart) adalah sebagai berikut:

a.Menghitung persentase kerusakan

Persentase kerusakan produk digunakan untuk melihat persentase kerusakan produk pada tiap sub group (hari)

$p=\frac{n p}{n}$

Sumber: Heizer dan Render (2006:268)

Keterangan:

$p$ : rata-rata produk rusak

$n_{p}$ : Jumlah gagal dalam sub grup

$n$ : Jumlah yang diperiksa dalam sub grup

Subgrup: hari/bulan/tahun ke-

Berdasarkan Tabel 1, data tersebut diolah dengan menggunakan bantuan Microsoft Excel 2016. Data yang diolah dapat dilihat pada tabel berikut:

Tabel 2. Persentase Produk Rusak AMDK 220ml

\begin{tabular}{cccc}
\hline Tgl & $\begin{array}{c}\text { Jumlah } \\
\text { Produksi } \\
(\mathrm{pcs})\end{array}$ & $\begin{array}{c}\text { Jumlah } \\
\text { Rusak } \\
(\mathrm{pcs})\end{array}$ & $\begin{array}{c}\text { Persentase } \\
\text { Produk Rusak } \\
(\%)\end{array}$ \\
\hline 13 & \multicolumn{2}{c}{ PRODUKSI DIALIHKAN } \\
14 & 48.480 & 1 & $0,002 \%$ \\
15 & 89.568 & 11 & $0,012 \%$ \\
16 & 118.992 & 20 & $0,017 \%$ \\
17 & 86.256 & 12 & $0,014 \%$ \\
18 & 110.448 & 75 & $0,068 \%$ \\
19 & & HARI MINGGU & \\
20 & 131.088 & 49 & $0,037 \%$ \\
21 & 107.760 & 55 & $0,051 \%$ \\
22 & 110.640 & 67 & $0,061 \%$ \\
23 & 127.680 & 139 & $0,109 \%$
\end{tabular}

PRODUKSI DIALIHKAN

HARI MINGGU

$\begin{array}{ccc}115.680 & 36 & 0,031 \% \\ 78.000 & 27 & 0,035 \% \\ 131.088 & 39 & 0,030 \% \\ 99.168 & 41 & 0,041 \%\end{array}$

HARI LIBUR PRODUKSI

HARI MINGGU

$\begin{array}{ccc}81.168 & 30 & 0,037 \% \\ 122.400 & 41 & 0,025 \% \\ 106.704 & 34 & 0,041 \%\end{array}$

PRODUKSI DIALIHKAN

$113.184 \quad 0,017 \%$

\begin{tabular}{cccc}
8 & 113.184 & 19 & $0,017 \%$ \\
9 & & HARI MINGGU & \\
10 & 113.808 & 35 & $0,031 \%$ \\
11 & 178.416 & 21 & $0,012 \%$ \\
\hline Total & 2.070 .528 & 752 & $0,036 \%$
\end{tabular}

Sumber: data diolah

b. Menghitung garis pusat / central line (CL)

Garis pusat merupakan garis yang mewakili rata-rata tingkat kerusakan dalam suatu proses produksi.

$C L=-p=\frac{\sum n p}{\sum n}$

Sumber: Heizer dan Render (2006:268) 
Keterangan:

CL : garis pusat / central line

$\sum_{n p}:$ Jumlah total yang rusak

$\sum n \quad:$ Jumlah total yang diperiksa

$$
C L=-p=\frac{752}{2.070 .528}=0,000363
$$

c.Menghitung batas kendali atas (UCL) dan batas kendali bawah (LCL)

Batas kendali atas dan batas kendali

ci. bawah merupakan indikator ukuran secara statistik sebuah proses bisa dikatakan terkendali atau tidak.

Batas kendali atas / Upper Control Limit

$$
U C L=-p+3 \frac{\sqrt{-p(1--p)}}{n}
$$

Sumber: Heizer dan Render (2006:268)

Keterangan:

$$
\text { UCL: Upper Control Limit / Batas Kendali Atas }
$$$$
\begin{array}{ll}
-p & : \text { rata-rata kerusakan produk } \\
n & : \text { total grup/sampel } \\
0,000363+3 & \frac{\sqrt{0,000363(1-0,000363)}}{89.568}=0,0005541
\end{array}
$$$$
0,000363+3 \frac{\sqrt{0,000363(1-0,000363)}}{48.480}=0,0006
$$

$d s t$

Batas kendali bawah / Lower Control Limit

$$
U C L=-p-3 \frac{\sqrt{-p(1--p)}}{n}
$$

Sumber: Heizer dan Render (2006:268)

Keterangan:

$$
\text { UCL: Upper Control Limit / Batas Kendali Atas }
$$

$$
\begin{array}{ll}
-p & : \text { rata-rata kerusakan produk } \\
n & : \text { total grup/sampel }
\end{array}
$$

$$
\text { 14-Mar }
$$$$
0,000363-3 \frac{\sqrt{0,000363(1-0,000363)}}{48.480}=0,0001
$$$$
0,000363-3 \frac{\sqrt{0,000363(1-0,000363)}}{89.568}=0,0001^{\prime}
$$

$d s t$

d. Membuat peta kendali $\mathrm{p}$ ( $p$-chart)

Setelah mendapatkan hasil perhitungan diatas maka selanjutnya adalah membuat peta kendali P. Peta kendali dibuat menggunakan bantuan program Minitab 17.

\section{Gambar 2. Peta Kendali (P-chart) AMDK 220ml Sumber: data diolah}

Berdasarkan peta kendali p-chart terdapat beberapa titik yang berada di luar batas kendali (UCL dan LCL). Terdapat tiga titik yang berada di luar batas kendali atas (UCL), enam titik yang berada di luar batas kendali bawah (LCL), dan sepuluh titik yang berada di dalam batas kendali sehingga dapat ditarik kesimpulan proses pengendalian kualitas tidak terkendali. Hal tersebut menyatakan bahwa pengendalian kualitas AMDK $220 \mathrm{ml}$ memerlukan adanya perbaikan. Perbaikan tersebut perlu dilakukan karena adanya titik yang berfluktuasi sangat tinggi dan tidak beraturan yang menunjukkan bahwa proses produksi masih mengalami penyimpangan.

\section{Mencari Faktor Penyebab Paling Dominan dengan Menggunakan Diagram Tulang Ikan (Fishbone Chart)}

a. Kemasan Bocor

Kerusakan berupa kemasan bocor pada AMDK 220ml disebabkan oleh faktor mesin dan bahan baku. Faktor mesin yaitu pengaturan suhu heater yang berubah dengan sendirinya (error) dikarenakan komponen pengatur suhu pada cup filling machine yang tidak stabil. Faktor mesin lainnya adalah kemasan yang terjepit pada persimpangan di conveyor.

Hal ini terjadi karena rangkaian conveyor dipasang tidak berbentuk garis lurus melainkan berkelok untuk menyesuaikan dengan alur produksi dan beberapa perangkat penunjang produksi. Bahan baku yang bermasalah adalah cup yang sudah mengalami kebocoran dari supplier. Cup yang bermasalah ini biasanya lolos dari proses sortasi karena terletak pada tengah-tengah slope (rangkaian cup yang berisi $80 \mathrm{pcs}$ ) sehingga masuk ke proses produksi dan mengakibatkan kerusakan.

Gambar 3. Diagram Sebab Akibat Kemasan Bocor Sumber: Hasil Observasi dan Wawancara (2017)

b. Kemasan Penyok

Penyebab kerusakan kemasan penyok pada AMDK 220ml disebabkan oleh faktor manusia, mesin, dan bahan baku. Kerusakan ini bisa terjadi baik sebelum proses pengisian air atau sesudahnya. Penyebab kerusakan sebelum proses produksi adalah dari faktor manusia dan bahan baku. Operator yang kurang berhati-hati dalam pemindahan karung yang berisi cup dari gudang bahan baku menuju ruang operator serta teledor ketika proses menaruh slope cup pada stocker merupakan penyebab kerusakan kemasan penyok pada faktor manusia. Pada faktor bahan baku, ditenggarai penyebab kerusakan ini adalah dari cup penyok yang berasal dari supplier. Penyebab kerusakan yang terjadi sesudah proses pengisian air adalah ketika produk berdesakan di persimpangan conveyor. Produk yang berdesakan secara berlebih akan membuat produk tertekan terlalu keras sehingga mengakibatkan kemasan penyok.

Gambar 4. Diagram Sebab Akibat Kemasan Penyok Sumber: Hasil Observasi dan Wawancara (2017) 


\section{c. Lid Miring}

Pada produk AMDK 220ml, lid mengacu pada tutup kemasan yang berupa lembaran plastik berbentuk bulat. Lid yang tercetak miring adalah lid yang tercetak secara tidak sesuai, baik dari desain gambar yang tidak simetris dengan bibir cup, atau cetakan miring tidak tepat pada cup.

Kerusakan ini terjadi karena beberapa hal, antara lain dari faktor manusia, mesin, dan metode. Operator yang kurang fokus dan tanggap dalam mengatur setelan perangkat lid (sensor correction, belt rem, dan roll lid) merupakan penyebab kerusakan dari faktor manusia, kemudian yang diakibatkan oleh faktor mesin terjadi saat pengepresan lid ke cup mengalami ketidaksesuaian yang disebabkan oleh pengaturan sensor mesin correction yang berubah secara acak (error). Penyebab dari faktor metode yaitu pengaturan belt rem yang kurang tepat. Hal ini akan mengakibatkan roll lid tidak dalam kepadatan yang tepat dan posisi yang tepat untuk di press sehingga berpotensi menimbulkan kerusakan lid miring.

Gambar 5. Diagram Sebab Akibat Lid Miring

Sumber: Hasil Observasi dan Wawancara (2017)

\section{d. Lid Terbuka}

Lid terbuka adalah keadaan ketika lid tidak menempel secara menyeluruh pada bibir cup sehingga air dalam cup tumpah. Penyebab jenis kerusakan ini adalah kurang panasnya sealer yang berfungsi untuk mempress lid sehingga yang suhu kurang akan mengakibatkan lid tidak menempel dengan baik, tekanan angin yang kurang dari kompresor sehingga proses sealing berjalan kurang sempurna, dan tidak sinkronnya pengaturan bucket dan sealer.

Gambar 6. Diagram Sebab Akibat Lid Terbuka

Sumber: Hasil Observasi dan Wawancara (2017)

\section{e. Lid Kendur}

Salah satu indikator lid yang baik adalah menempel erat pada produk. Ketika lid pada produk meregang atau kendur maka produk tersebut akan di reject. Lid yang kendur akan menurunkan kualitas produk terutama pada tampilan produk yang menjadi kurang menarik sehingga berpotensi menurunkan minat pembelian konsumen. Lid yang kendur diakibatkan oleh faktor mesin. Faktor ini terjadi pada dua tempat yaitu pada tekanan angin yang kurang pada mesin sealer sehingga lid tidak terpress dengan sempurna. Kemudian tempat lain yang mengakibatkan lid kendur adalah ketika produk jadi terjepit di persimpangan conveyor kemudian terdesak oleh produk lain secara terus-menerus.

Gambar 7. Diagram Sebab Akibat Lid Kendur Sumber: Hasil Observasi dan Wawancara (2017)

\section{f. Lid Bocor}

Penyebab kerusakan ini adalah faktor mesin dan faktor bahan baku. Pada faktor mesin, sealer yang kurang panas akan menyebabkan lid kurang lengket dan rawan mengelupas. Pada faktor bahan baku kerusakan lid bocor disebabkan oleh lid yang bermasalah yaitu lid yang tipis (kurang dari 55 mikron) dari supplier. Lid tipis akan mengakibatkan lid rawan bocor ketika terkena benturan (jatuh dari bucket pada conveyor di cup filling machine atau dari conveyor ke keranjang penampungan).

Gambar 8. Diagram Sebab Akibat Lid Bocor

Sumber: Hasil Observasi dan Wawancara (2017)

\section{g. Trimming}

Lid normal pada produk jadi terpotong berbentuk bulat pada masing-masing produk. Ketika terjadi kerusakan trimming, lid-lid tersebut tidak terpotong dengan pas sehingga lid pada cup menyambung satu sama lain. Trimming terjadi karena faktor mesin yaitu pada mesin trimming yang mengalami gangguan. Gangguan tersebut antara lain tekanan angin pada mesin yang kurang, tidak sinkronnya antara pisau trimming dan bucket serta pisau pada mesin trimming yang kurang tajam.

Gambar 8. Diagram Sebab Akibat Trimming

Sumber: Hasil Observasi dan Wawancara (2017)

h. Benda Asing

Proses produksi AMDK $220 \mathrm{ml}$ menghasilkan sisa proses dari bahan baku. Sisa bahan baku tersebut berupa potongan lid yang berasal dari proses trimming dan di kategorikan sebagai benda asing. Selain berasal dari sisa proses produksi, benda asing tersebut bisa berasal dari cup yang kotor dan tidak terdeteksi pada proses sortasi. Benda asing baik dari sisa proses produksi atau dari cup yang kotor akan masuk ke dalam produk ketika proses filling (pengisian air). Produk yang terdapat benda asing dikategorikan rusak dan harus di reject. Benda asing yang tidak sempat masuk saat proses filling, akan menempel pada bucket dan pada gilirannya akan masuk ke dalam produk ketika terdorong air.

Gambar 9. Diagram Sebab Akibat Benda Asing Sumber: Hasil Observasi dan Wawancara (2017)

\section{Membuat Rekomendasi/Usulan Perbaikan Kualitas dengan Metode 5S dan Metode 5W+1H}

a.Metode 5S

Metode ini digunakan untuk menumbuhkan kebiasaan baik dalam produksi guna memperlancar berjalannya proses produksi dan meminimalkan persentase kerusakan produk. Walaupun belum mendapat sertifikasi training 5S, penerapan metode 5S sendiri pada PT. Tujuh Impian Bersama Kabupaten Jember sudah di aplikasikan pada semangat kerja berdasar poin-poin 5S antara lain:

1.Seiri (Ringkas)

Menyisihkan barang-barang yang tidak diperlukan di tempat kerja

Tabel 3. Penerapan Seiri

\begin{tabular}{ll}
\hline Pelaksanaan & Departemen \\
\hline - Pemisahan cup dan lid yang akan & - Ruang Operator \\
masuk ruang operator dan cup dan & \\
lid yang berada di gudang. & \\
- Pemisahan karton yang akan & - Ruang Operator \\
digunakan dan berada di gudang & \\
- Pemindahan karton yang berisi & - Ruang Operator \\
produk jadi ke gudang. & \\
\hline
\end{tabular}

Sumber: Hasil Observasi dan Wawancara (2017) 


\section{Seiton (Rapi)}

Menata barang-barang yang diperlukan supaya mudah ditemukan oleh siapa saja bila diperlukan.

Tabel 4. Penerapan Seiton

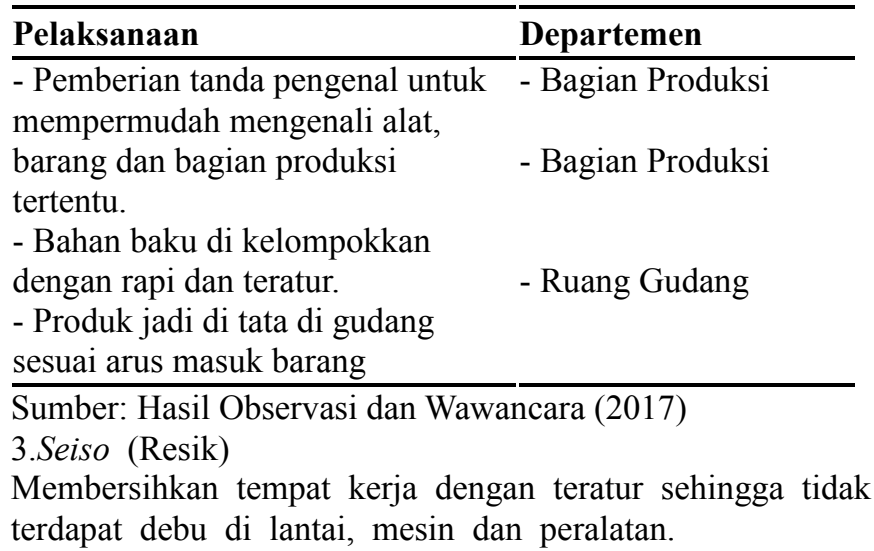

Tabel 5. Penerapan Seiso

\begin{tabular}{ll}
\hline Pelaksanaan & Departemen \\
\hline - Setiap karyawan sebelum & - Bagian Produksi \\
memasuki ruang produksi di & \\
haruskan mencuci tangan di & \\
wastafel yang disediakan. & \\
- Khusus untuk staf laboratorium & - Bagian Produksi \\
dan operator di haruskan & \\
melakukan sterilisasi dengan & \\
antiseptic dan memakai jas & - Bagian Produksi \\
laboratorium. & \\
- Penyediaan sapu, pel, dan kain di & \\
sekitar tempat kerja. & \\
\hline Sumber: Hasil Observasi dan Wawancara (2017) & \\
4.Seiketsu (Rawat)
\end{tabular}

Memelihara taraf kepengurusan rumah tangga yang baik dan organisasi tempat kerja setiap saat.

\section{Tabel 6. Penerapan Seiketsu}

\begin{tabular}{l}
\hline Pelaksanaan \\
\hline - Pembiasaan karyawan untuk \\
bekerja secara rapi, mengembalikan \\
alat sesuai posisinya semula dan \\
membiasakan membersihkan diri \\
baik sebelum atau sesudah proses \\
produksi. \\
- Pemantauan rutin setiap harinya \\
baik oleh kepala produksi dan \\
supervisor QC (quality control) \\
untuk melakukan tindak lanjut jika \\
ditemukan hal yang mengganggu \\
berlangsungnya proses produksi.
\end{tabular}

Sumber: Hasil Observasi dan Wawancara (2017)

1.Shitsuke (Rajin)

Memberikan penyuluhan kepada semua orang agar mematuhi disiplin pengurusan rumah tangga yang baik atas kesadaran sendiri.

Tabel 7. Penerapan Shitsuke

\begin{tabular}{ll}
\hline Pelaksanaan & Departemen \\
\hline - Diadakan apel pagi rutin untuk & - Semua Bagian \\
mempererat hubungan antara & \\
karyawan dari berbagai bagian. & \\
- Sering diadakan penetapan target & - Semua Bagian \\
tertentu antar divisi untuk memacu & \\
semangat berkembang. & \\
- Penetapan karyawan teladan. & - Semua Bagian \\
\hline
\end{tabular}

Sumber: Hasil Observasi dan Wawancara (2017)

a.Metode $5 \mathrm{~W}+1 \mathrm{H}$

Metode $5 \mathrm{~W}+1 \mathrm{H}$ digunakan untuk melakukan investigasi dan penelitian terhadap masalah yang terjadi dalam proses produksi.

1.Rekomendasi Perbaikan Menggunakan 5W+1H Pada Kerusakan Kemasan Bocor

Rekomendasi perbaikan yang dilakukan dengan pendekatan $5 \mathrm{~W}+1 \mathrm{H}$ pada kerusakan kemasan bocor yaitu dari faktor mesin melalui pengecekan setelan suhu pada heater dilakukan secara rutin untuk memastikan suhu sesuai standard operational procedure (SOP), kemudian dilakukan pemasangan baling-baling pada conveyor untuk mengurai produk sehingga arus produk menjadi lancar. Rekomendasi perbaikan pada faktor bahan baku yaitu pengecekan dengan sortasi dan sampling dilakukan lebih teliti meliputi tampilan fisik dan gramature cup $(2,5 \mathrm{~g})$. Pengecekan dilakukan sebanyak dua kali, yaitu ketika bahan baku datang dari pengiriman dan sebelum proses produksi berlangsung. Hal ini dilakukan sebagai tindakkan pencegahan untuk memperkecil jumlah cup bocor yang masuk ke dalam proses.

2.Rekomendasi Perbaikan Menggunakan 5W+1H Pada Kerusakan Kemasan Penyok

Rekomendasi perbaikan yang dilakukan dengan pendekatan $5 \mathrm{~W}+1 \mathrm{H}$ pada kerusakan kemasan penyok yaitu dari faktor manusia dengan lebih berhati-hati dalam melakukan pemindahan bahan baku dari gudang menuju ruang operator serta dalam menaruh slope cup ke stocker. Pengawas produksi dirasa perlu meningkatkan pengawasan terhadap kinerja dan secara berkala melakukan briefing kepada pekerja bagian produksi dan operator untuk memastikan mereka melakukan pekerjaan dengan baik dan benar. Kemudian pada faktor mesin yaitu pemasangan baling-baling pada conveyor untuk mengurai produk sehingga arus produk menjadi lancar. Pada faktor bahan baku, rekomendasi perbaikan yaitu pengecekan dengan sortasi dan sampling dilakukan lebih teliti meliputi tampilan fisik dan gramature cup $(2,5 \mathrm{~g})$. Pengecekan dilakukan sebanyak dua kali, yaitu ketika bahan baku datang dari pengiriman dan sebelum proses produksi berlangsung. Hal ini dilakukan sebagai tindakkan pencegahan untuk memperkecil jumlah cup penyok yang masuk ke dalam proses produksi.

3.Rekomendasi Perbaikan Menggunakan 5W+1H Pada Kerusakan Lid Miring

Rekomendasi perbaikan yang dilakukan dengan pendekatan $5 \mathrm{~W}+1 \mathrm{H}$ pada kerusakan lid miring yaitu dari faktor manusia adalah lebih fokus serta tanggap dalam mengatur setelan perangkat lid (sensor correction, belt rem, dan roll lid) dan pengawas produksi meningkatkan pengawasan terhadap kinerja dan secara berkala melakukan briefing. Kemudian dari faktor mesin yaitu setting ulang secara berkala untuk 
menyinkronkan sensor mesin correction dengan bucket agar lid yang terpress nantinya benar-benar presisi dan tepat. Pada faktor metode dengan setting ulang secara berkala pada belt rem untuk mengatur tingkat ketegangan roll lid agar berada di tingkat ketegangan yang tepat.

4.Rekomendasi Perbaikan Menggunakan 5W+1H Pada Kerusakan Lid Terbuka

Rekomendasi perbaikan yang dilakukan dengan pendekatan $5 \mathrm{~W}+1 \mathrm{H}$ pada kerusakan lid terbuka dari faktor mesin yaitu setting ulang secara berkala pada kompressor untuk memastikan tekanan angin pada keadaan optimal, menyinkronkan bucket dan sealer agar lid terpress dengan tepat pada cup, dan rutin mengatur suhu pada sealer sesuai standard operational procedure (SOP).

5.Rekomendasi Perbaikan Menggunakan 5W+1H Pada Kerusakan Lid Kendur

Rekomendasi perbaikan yang dilakukan dengan pendekatan $5 \mathrm{~W}+1 \mathrm{H}$ pada kerusakan lid kendur yaitu dari faktor mesin adalah dengan pengaturan tekanan angin dengan menyetel kompressor secara berkala untuk memastikan tekanan angin berada dalam kondisi optimal sesuai standard operational procedure (SOP) dan pemasangan baling-baling untuk mengurai kepadatan arus produk di conveyor.

6.Rekomendasi Perbaikan Menggunakan 5W+1H Pada Kerusakan Lid Bocor

Rekomendasi perbaikan pada kerusakan lid bocor yaitu pada perbaikan faktor mesin dan faktor bahan baku. Pada faktor mesin adalah dengan rutin mengatur suhu pada sealer sesuai standard operational procedure. Kemudian pada faktor bahan baku yaitu lid yang bermasalah melalui komunikasikan dengan supplier mengenai spesifikasi dan ketentuan kerusakan terhadap roll lid dan mengenai ketentuan retur terhadap lid yang bermasalah.

7.Rekomendasi Perbaikan Menggunakan 5W+1H Pada Kerusakan Trimming

Rekomendasi perbaikan yang dilakukan dengan pendekatan $5 \mathrm{~W}+1 \mathrm{H}$ pada kerusakan trimming adalah dengan pengaturan berkala tekanan angin pada kompressor, menyinkronkan setelan bucket dan pisau trimming, dan mengasah pisau trimming untuk mempertahankan ketajaman pisau.

8.Rekomendasi Perbaikan Menggunakan 5W+1H Pada Kerusakan Benda Asing

Rekomendasi perbaikan yang dilakukan dengan pendekatan $5 \mathrm{~W}+1 \mathrm{H}$ pada kerusakan benda asing yaitu dari faktor bahan baku dengan pengecekan lebih teliti dan dilakukan sebanyak dua kali, yaitu ketika bahan baku cup datang dari pengiriman, dan sebelum proses produksi berlangsung, dari faktor metode yaitu membersihkan potongan lid yang terlihat mengapung karena terangkat air pada proses filling untuk memastikan benda tersebut tidak masuk ke dalam produk.

\section{Pembahasan}

Sebagai perusahaan yang bergerak di bidang AMDK, PT. Tujuh Impian Bersama memiliki komitmen menjadi perusahaan yang memberikan hasil yang berkualitas tinggi. Salah satu usaha perusahaan untuk mewujudkan komitmen tersebut adalah dengan menerapkan pengendalian kualitas pada keseluruhan proses produksi AMDK mulai dari penyiapan bahan baku hingga produk jadi. Proses produksi dilakukan secara higienis melalui mesin reversis osmosis (RO), 3 tahap macrofiltrasi dan 5 tahap microfiltrasi serta sterilisasi ultraviolet dan ozonisasi.

Statistical process control (SPC) merupakan metode pengendalian kualitas dengan alat bantu statistik dimana alat proses produksi dikendalikan kualitasnya mulai dari awal produksi, pada saat proses produksi berlangsung sampai dengan produk jadi. Sebelum dilempar ke pasar, produk yang telah diproduksi diinspeksi terlebih dahulu, dimana produk yang baik dipisahkan dengan yang rusak, sehingga produk yang dihasilkan jumlahnya berkurang.

Sedangkan Kaizen sendiri merupakan istilah dalam bahasa Jepang terhadap konsep Continous Incremental Improvement. Kai berarti perubahan dan Zen berarti baik. Kaizen berarti penyempurnaan yang berkesinambungan yang melibatkan setiap orang. (Imai, 2001). Penelitian menggunakan alat statistik ini pernah dilakukan oleh Joko Susetyo, Winarni, Catur Hartanto (2011) dan Muhammad Nur Ilham (2012) Secara umum, faktor utama yang menyebabkan kerusakan produk dari kedua penelitian tersebut adalah disebabkan oleh faktor manusia dan mesin.

Pengendalian kualitas telah dilakukan oleh PT. Tujuh Impian Bersama untuk memproduksi AMDK mulai dari air baku, proses produksi, hingga pengepakan untuk menekan tingkat kerusakan produk. Standar yang telah dipenuhi perusahaan antara lain Sertifikasi Manajemen Mutu ISO 9001:2008 No. SSMM-035, SNI No. 01-3553-2006, Izin BPOM RI MD No. 265213006124, dan Sertifikasi Halal MUI No. 07120034190616. Perusahaan juga telah bergabung dengan ASPADIN (Asosiasi Pengusaha Air Minum Dalam Kemasan Indonesia). Setelah dilakukan pengamatan dan pengumpulan data selama penelitian menyatakan bahwa kerusakan produk melebihi batas kendali yang ditetapkan perusahaan. Jadi, jika hal tersebut dibiarkan terjadi secara terus-menerus maka akan menyebabkan kerugian bagi perusahaan. Oleh karena itu perlu dilakukan suatu tindakan untuk mengatasi permasalahan tersebut.

Dari hasil analisi menggunakan Statistical Process Control yang dilakukan pada penelitian ini dapat diketahui jenis-jenis kerusakan produk serta faktor-faktor yang menyebabkan kerusakan tersebut. Secara umum faktor penyebab kerusakan AMDK disebabkan oleh faktor mesin, bahan baku, manusia dan metode. Hasil perhitungan peta kendali p-chart menyatakan bahwasanya kerusakan produk tidak dalam batas kendali yang ditentukan, bahkan cenderung tidak terkendali karena titik-titik berfluktuasi tidak beraturan dan berada keluar dari batas kendalinya.

Jenis kerusakan yang paling besar yaitu kemasan penyok sebanyak 239pcs, hal tersebut disebabkan oleh operator yang kurang berhati-hati dalam pemindahan bahan baku serta teledor ketika proses menaruh slope cup pada stocker, cup penyok yang berasal dari supplier dan produk berdesakan di persimpangan conveyor. Jumlah terbanyak kedua yaitu lid miring sebanyak 131 pcs. Penyebab dari lid miring kerusakan ini terjadi karena beberapa hal, antara lain operator yang kurang fokus dan tanggap dalam mengatur setelan perangkat lid (sensor correction, belt rem, dan roll lid), pengaturan sensor mesin correction yang berubah secara acak (error) dan pengaturan belt rem yang kurang tepat. Kerusakan yang 
paling kecil yaitu lid kendur sebanyak 15pcs. Penyebab lid kendur adalah tekanan angin yang kurang pada mesin sealer dan ketika produk jadi terjepit di persimpangan conveyor. Jumlah kerusakan yang telah dijelaskan tadi merupakan jumlah kerusakan produk pada pada tanggal 13 Maret-11 April 2017. Dengan penelusuran lebih lanjut dapat disusun rekomendasi atau usulan tindakan perbaikan kualitas yang bisa dilakukan oleh perusahaan untuk menekan tingkat kerusakan yang terjadi.

Berdasarkan alat-alat implementasi kaizen maka rekomendasi perbaikan yang diperoleh adalah perawatan rutin dan penyetelan ulang terhadap mesin produksi, pemilihan lebih teliti terhadap supplier dengan standar yang lebih ketat, dan peningkatan kinerja sumber daya manusia melalui pengawasan dan briefing.

Analisis yang telah dilakukan dengan menggunakan Statistical Process Control dan Kaizen diharapkan dapat menjadi suatu masukan yang bersifat membangun bagi perusahaan untuk senantiasa meningkatkan kualitas produk melalui menekan penyebab kerusakan produk untuk mengurangi tingkat kerusakan produk menjadi serendah mungkin.

\section{Simpulan}

Berdasarkan hasil peta kendali p-chart dapat dilihat bahwa pengendalian kualitas produk AMDK 220ml berada di luar batas kendali. Hal ini dapat dilihat pada grafik peta kendali yang menunjukkan masih banyak titik-titik berfluktuasi dan tidak beraturan di luar batas kendali. Dari 19 titik terdapat 9 titik yang berada di luar batas kendali. Titik-titik tersebut mengindikasikan bahwa proses berada dalam keadaan tidak terkendali atau masih mengalami penyimpangan.

Berdasarkan hasil analisis diagram sebab akibat dapat diketahui faktor-faktor penyebab kerusakan produk AMDK $220 \mathrm{ml}$ yaitu berasal dari faktor manusia, mesin, bahan baku, dan metode. Faktor manusia yaitu operator dan pekerja bagian produksi yang kurang fokus dan teledor. Faktor mesin yaitu pengaturan perangkat mesin (heater, sealer, sensor correction, kompresor, kesesuaian bucket dengan sealer, kesesuaian bucket dengan pisau trimming) yang berubah dengan sendirinya (error) setelah disetel dan produk yang terjepit di persimpangan conveyor. Faktor bahan baku yaitu bahan baku yang bermasalah (cup dan lid) dari supplier. Dan faktor metode yaitu pengaturan belt rem yang kurang tepat.

Solusi perbaikan yang dapat dilakukan untuk mengurangi tingkat kerusakan pada produk AMDK 220ml antara lain: pekerja bagian produksi dan operator di himbau untuk lebih berhati-hati dalam bekerja, dilakukan pengawasan secara berkala dan rutin melakukan briefing, melakukan setelan ulang pada perangkat mesin (heater, sealer, sensor correction, kompresor, kesesuaian bucket dengan sealer, kesesuaian bucket dengan pisau trimming ) yang bermasalah, pemasangan baling-baling pada conveyor dan melakukan pemeriksaan lebih teliti terhadap bahan baku serta mengevaluasi secara rutin supplier.

\section{Ucapan Terima Kasih}

Penulis mengucapkan terima kasih kepada Fakultas Ekonomi dan Bisnis Universitas Jember sebagai wadah menimba dan mengasah ilmu. Kepada karyawan-karyawan PT . Tujuh Impian Bersama Kabupaten Jember terimakasih banyak atas bantuan dan kerjasamanya. Selain itu penulis juga mengucapkan terima kasih kepada orang tua dan temanteman untuk doa dan dukungannya.

\section{Referensi}

Alisjahbana, Juita. 2005. Evaluasi Pengendalian Kualitas Total Produk Pakaian Wanita Pada Perusahaan Konveksi. Jurnal Ventura. 8(1): 1-10.

Heizer, Jay. dan Render. Barry. 2006. Manajemen Operasi Buku 1. Edisi Ketujuh. Jakarta: Salemba Empat.

Ilham, Muhammad. Nur. 2012. Analisis Pengendalian Kualitas Produk dengan Menggunakan Statistical Process Control (SPC) pada PT. Bosowa Media Grafika (Tribun Timur). Tidak Dipublikasikan. Skripsi. Makassar: Universitas Hasanuddin.

Imai, Masaaki. 2001. Kaizen (Ky'zen) Kunci Sukses Jepang Dalam Persaingan. Jakarta: PPM.

Keputusan Menteri Perindustrian dan Perdagangan Republik Indonesia Nomor 167 Tahun 1997. Persyaratan Teknis Industri dan Perdagangan Air Minum Dalam Kemasan. 28 Mei 1997. Jakarta.

Susetyo, Joko., Winami, dan Catur. Hartanto. 2011. Aplikasi Six Sigma DMAIC dan Kaizen Sebagai Metode Pengendalian dan Perbaikan Kualitas. Jurnal Teknologi. 4(1): 78-87. 